\title{
Effects of Wind Speed and Direction on Eddy Fluxes over a Larch Plantation
}

\author{
Ryuichi HIRATA*, Takashi HIRANO*, Keiji OKADA*, Yasumi FUJINUMA**, \\ Koh INUKAI $^{* *}$, Nobuko SAIGUSA ${ }^{* *}$ and Susumu YAMAMOTO ${ }^{* * *}$ \\ - Graduate School of Agriculture, Hokkaido University, Sapporo, 060-8589, Japan \\ - Center for Global Environmental Research, National Institute for Environmental Studies \\ Tsukuba, 305-8506, Japan \\ "*. National Institute of Advanced Industrial Science and Technology, Tsukuba, 305-8569, Japan
}

\begin{abstract}
The closure of energy balance is a useful measure for evaluating the quality of eddy flux measurements. However, it was reported that eddy energy flux became imbalanced by available energy at many study sites. The energy imbalance is of a great interest to the flux community, whereas the problem remains unsolved. In this paper, we investigate the effects of wind speed, wind direction and phenology on eddy energy fluxes measured over a larch plantation to understand the mechanism of the energy imbalance. Flow distortion by the tower affected energy balance closure. If wind directions through the tower were excluded, energy balance was lower than the average of FLUXNET sites (Wilson et al., 2002). Energy balance was more closed in the summer than in the defoliate season. The larger imbalance of energy balance closure through defoliation was partly due to the increasing spatial variability of net radiation. Energy balance closure became worse under the conditions of low wind speed. Both sensible and latent heat fluxes increased with friction velocity.
\end{abstract}

Key words: Eddy energy fluxes, Energy balance closure, Friction velocity

\section{Introduction}

The closure of energy balance is a useful measure for evaluating the quality of eddy flux measurements (Aubinet et al., 2000). However, it was reported that eddy energy flux became imbalanced by available energy at many study sites (Wilson et al., 2002). The energy imbalance is of a great interest in the flux community, whereas the problem remains unsolved. Tomakomai Flux Research Site (FRS), a larch plantation, has an ideal terrain for measuring eddy fluxes (Fujinuma et al., 2001), in which energy balance is almost closed (Miura et al., 2003). In this paper, we investigate the effects of wind speed, wind direction and phenology on eddy fluxes measured over the larch plantation to understand the mechanism of the energy imbalance using data from July to December 2002.

\section{Materials and Methods}

\subsection{Site description}

The study site is Tomakomai FRS, a Japanese larch plantation (Larix kaempferi Sarg.) in Tomakomai, Hokkaido, Japan $\left(42^{\circ} 44^{\prime} \mathrm{N}, 141^{\circ} 31^{\prime} \mathrm{E}\right)$. The terrain is almost flat, with a slope between $1^{\circ}$ and $2^{\circ}$. The area of the larch forest is about 100 ha, and the canopy height is $15-16 \mathrm{~m}$. Canopy LAI reached $2.5 \mathrm{~m}^{2} \mathrm{~m}^{-2}$ at the maximum in summer. There were scattered deciduous broadleaf trees (Betula ermanii, Betula platyphylla, and Ulmus japonica) and sparsely distributed spruce (Picea jezoensis). A 42-m tower was built near the forest center for measurements of fluxes and meteorology. Fetch was between $300 \mathrm{~m}$ for the north and $800 \mathrm{~m}$ for the west; it was $350 \mathrm{~m}$ for the south, which was the dominant wind direction. The forest floor was thickly covered with understory species, which mainly consist of fern (Dryopteris crassirhizoma) and Pachysandra terminalis with the maximum height of 0.9-1.4 $\mathrm{m}$ and maximum LAI of $3.6 \mathrm{~m}^{2} \mathrm{~m}^{-2}$ in July. In 2002 , larch leaves turned completely yellow by 3 November, and larch trees defoliated by 18 November in 2002. Continuous snow cover began on 17 December (Tanaka et al., 2003). Hirano et al. (2003) described site characteristics in detail.

Figure 1 shows the relative frequency of wind direction, which was divided into the north, east, south and western directions. The southern wind, $67 \%$, is the dominant wind direction in summer (July and August). From autumn to winter, western wind frequency increased instead of there being a decrease in southern wind frequency.

\subsection{Measurement of eddy fluxes}

Sensible heat flux $(H)$ and latent heat flux (IE) have been measured over the canopy by the eddy covariance technique since 2000 (Hirano et al., 2003). The fluctuations of wind speed and virtual temperature were measured with a $3 \mathrm{D}$ sonic anemometerthermometer (DA600, Kaijo), and $\mathrm{CO}_{2}$ and water vapor fluctuations were measured with an open-path $\mathrm{CO}_{2} / \mathrm{H}_{2} \mathrm{O}$ analyzer (LI7500, Licor) at a height of $27 \mathrm{~m}$. 


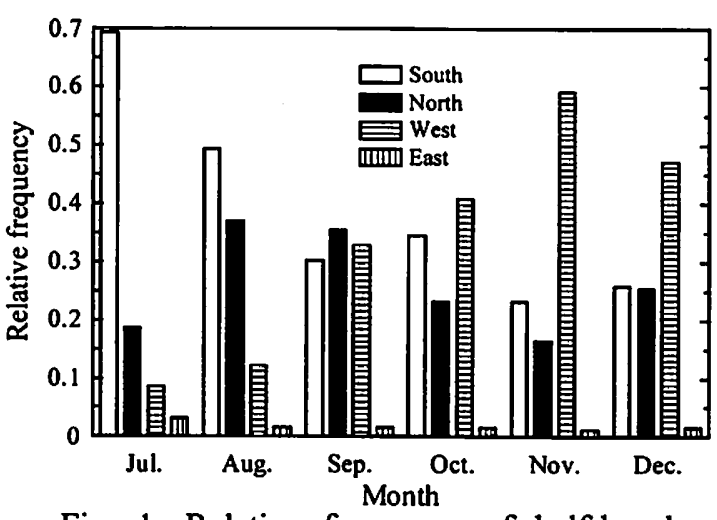

Fig. 1. Relative frequency of half-hourly wind direction for each month in 2002.

Data were sampled at $10 \mathrm{~Hz}$ through a low-pass filter with a cut-off frequency of $5 \mathrm{~Hz}$, and half-hourly averages of fluxes were calculated without trend removal; double rotation and WPL corrections were applied, and sensor span and separation between sensors were corrected. To minimize flow distortion by the tower, the flux sensors were mounted on a 2-m long boom projecting to the west. Data with an eastern wind blowing from the tower were excluded to remove the influence of the tower. We also excluded data when tilt angles of wind were out of $\pm 10^{\circ}$. Details of flux and meteorological measurements were described in a study by Hirano et al. (2003). A flux footprint analysis using the model of Korman and Mexiner (2001) showed that $80 \%$ of eddy fluxes measured at 27 $\mathrm{m}$ in the daytime typically originated within about 200 $\mathrm{m}$, whereas they originated within about $500 \mathrm{~m}$ in the nighttime.

Net radiation $\left(R_{\mathrm{n}}\right)$ was measured at $42 \mathrm{~m}$ with a radiometer (MR40, Eko, Japan), which was mounted on a 2-m long boom projecting to the south. Soil heat flux at ground surface $(G)$ was calculated by adding heat storage change in the topsoil layer above heat plates (MF-81, Eko, Japan), which were installed at depth of $0.05 \mathrm{~m}$, to measure conductive heat flux. Total heat storage flux $(S)$ in a column standing on a ground surface up to the flux measuring height of $27 \mathrm{~m}$ was calculated as the sum of heat storage changes in boles, leaves and air in the column. Miura et al. (2003) described the measurement and calculation of $S$ in detail.

\subsection{Analysis of energy balance closure}

We evaluated energy balance closure by two methods using data measured form July to December 2002. The first one used a slope of linear regression between eddy energy fluxes $(H+\mathrm{IE})$ and available energy $\left(R_{\mathrm{n}}-G-S\right)$ on a basis of half-hourly mean. Ideal closure is represented by a slope of one and an intercept of zero. The second method used energy balance ratio (EBR) derived from sum of eddy energy fluxes and available energy.

$$
\mathrm{EBR}=\frac{\sum(H+\mathrm{IE})}{\sum\left(R_{\mathrm{n}}-G-S\right)}
$$

The EBR method produces an overall evaluation of energy balance closure at longer time scales by averaging over random errors in the half-hour measurements. We primarily used the regression method to discuss energy balance closure in this study.

\section{Results and Discussion}

\subsection{Effect of wind direction}

The effects of wind direction were examined to assess data quality. Figure 2 shows the winddirectional distribution of EBR when available energy was above $200 \mathrm{~W} \mathrm{~m}^{-2}$. If we exclude wind directions of $19^{\circ}$ and $63^{\circ}$ through the tower, and $30^{\circ}$ on either side following the suggestion of Kaimal and Finnigan (1994), EBR was between 0.75 and 1.20. Consequently, we excluded data for wind direction between $10^{\circ}$ and $90^{\circ}$ to avoid the small EBR, which was probably caused by the flow distortion; excluded data account for $9.8 \%$ of all data.

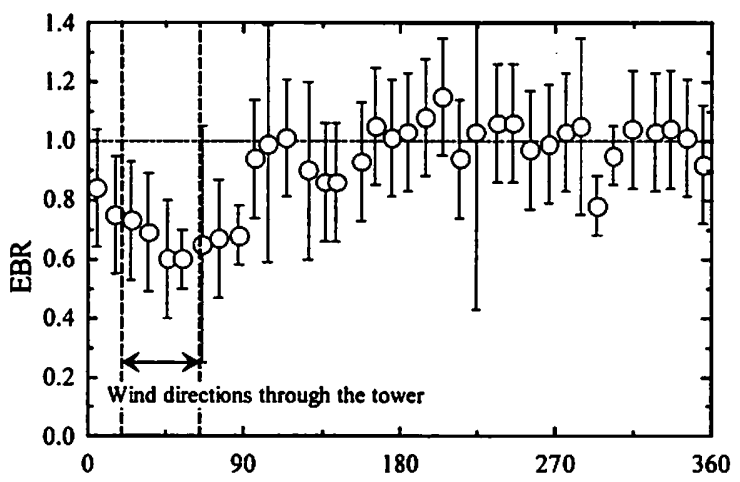

Fig. 2. Wind-directional distribution of EBR. Data were divided into direction classes of $10^{\circ}$ from July through the first half of November under the condition of available energy being above $200 \mathrm{~W} \mathrm{~m}^{-2}$. Vertical bars denote standard variation.

\subsection{Seasonal variation in energy balance closure}

The slope and intercept were 0.94 and $6.3 \mathrm{~W} \mathrm{~m}^{-2}$, respectively for all available data from July to December 2002; $r^{2}$ was 0.93 . The slope and intercept during the daytime $\left(R_{\mathrm{n}}-G-S>50 \mathrm{~W} \mathrm{~m}^{-2}\right)$ and nighttime $\left(R_{\mathrm{n}}-G-S<-20 \mathrm{~W} \mathrm{~m}^{-2}\right)$ were 0.98 and -6.6 $\mathrm{W} \mathrm{m} \mathrm{m}^{-2}$, and 0.97 and $14.2 \mathrm{~W} \mathrm{~m}^{-2}$, respectively. The mean slope at FLUXNET forest sites was $0.79 \pm 0.01$ with a range between 0.53 and 0.99 , and the mean intercept was $3.7 \pm 2.0 \mathrm{~W} \mathrm{~m}^{-2}$ with a range between 32.9 and $36.9 \mathrm{~W} \mathrm{~m}^{-2}$ (Wilson et al., 2002). On the other hand, EBR calculated using whole day data was 0.62 , which was smaller than the mean EBR of 0.84 at FLUXNET forest sites, ranging from 0.34 to 1.69 (Wilson et al., 2002). EBR during the daytime and nighttime was 0.93 and 0.57 , respectively. Consequently, energy balance was almost closed in this forest during the daytime. 
Figure 3 shows seasonal variation in the slope obtained by forcing the intercept to be zero, which represents energy balance closure for each moth. During summer (July and August), the balance was almost closed. In contrast, from November to December, the energy balance closure became lower with defoliation. This energy balance closure in the defoliate period was partly due to difference in the source area between eddy fluxes and $R_{\mathrm{n}}$. During defoliation, the forest canopy became more spatially heterogeneous because of scattered leaves. In addition, the forest floor contributed much more to energy exchange. The radiational characteristic of the forest floor was more spatially variable than that of the canopy. These facts suggest that the spatial variation of $R_{\mathrm{n}}$ is larger in the defoliate period.

We neglected the latent heat of snow melt and freeze, although snow covered the forest floor in late December. This neglect is one of the reasons for the lowest energy balance closure in December.

\subsection{Effect of wind speed}

The effects of wind speed on energy balance closure were investigated using data in July and August, when the energy balance was almost closed (Fig. 3). Figure

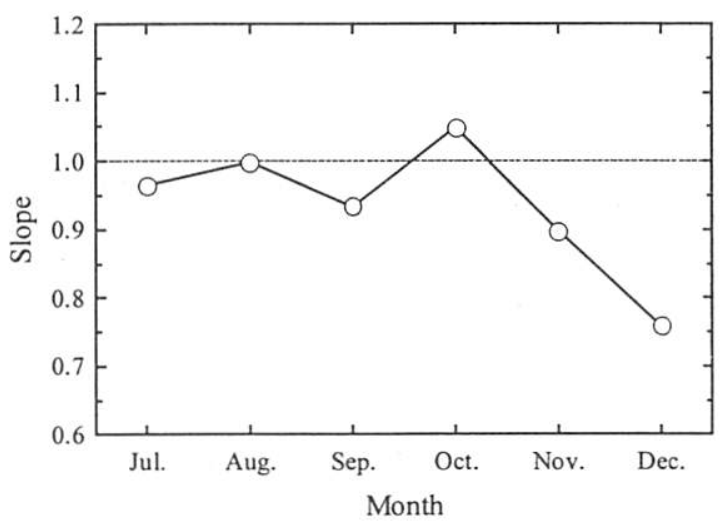

Fig. 3. Seasonal variation in the slope of the linear regression between eddy energy fluxes and available energy with zero intercept.
4 (a) shows the relationship between eddy energy fluxes $(H+\mathrm{IE})$ and available energy $\left(R_{\mathrm{n}}-G-S\right)$ categorized into friction velocity $\left(u^{*}\right)$ classes of $0.2 \mathrm{~m}$ $\mathrm{s}^{-1}$. Both the slope and intercept increased with $u^{*}$. The ratios of $H$ and $\mathrm{IE}$ to available energy also depended on $u^{*}$, respectively. The slope of the former relationship increased with $u^{*}$, and the intercept conversely decreased (Fig. 4 (b)). On the other hand, the slope of the later relationship decreased when $u^{*}$ was above $0.2 \mathrm{~m} \mathrm{~s}^{-1}$, although the intercept increased with $u^{*}$ (Fig. 4 (c)).

The effect of $u^{*}$ on energy balance closure was further analyzed using the EBR method by classifying available energy into three categories (Fig. 5 (a)). EBR increased with $u^{*}$ in the same manner as the regression slopes. EBR was close to one when $u^{*}$ was between 0.4 and $0.6 \mathrm{~m} \mathrm{~s}^{-1}$. Eddy energy fluxes were underestimated and overestimated at $u^{*}$ below $0.2 \mathrm{~m} \mathrm{~s}^{-1}$ and above $0.6 \mathrm{~m} \mathrm{~s}^{-1}$, respectively. EBR was more dependent on $u^{*}$ when available energy was below $200 \mathrm{~W} \mathrm{~m}^{-2}$. The dependence became weak with available energy. The ratio of $\mathrm{IE}$ to available energy was larger than that of $H$. The $H$ ratio increased with available energy (Fig. 5 (b)), whereas the $\mathrm{IE}$ ratio decreased (Fig. 5 (c)). When available energy was below $200 \mathrm{~W} \mathrm{~m}^{-2}$, the dependence of both the ratios on $u^{*}$ was strong. The dependence of the $\mathrm{IE}$ ratio became very weak when available energy was larger than 400 $\mathrm{W} \mathrm{m}{ }^{-2}$. Consequently, the dependence of EBR on $u^{*}$ was more affected by $H$ than IE when available energy was large. One of the reasons of the weak dependence of $\mathrm{IE}$ was stomata closure caused by water stress under high light conditions.

In the nighttime, EBR decreased under a strong turbulent condition with high $u^{*}$, although it increased up to 0.93 with $u^{*}$ to $0.4 \mathrm{~m} \mathrm{~s}^{-1}$ (Fig. 6). The $H$ ratio increased with $u^{*}$ and the $\mathrm{IE}$ ratio of became more negative. Under a strong turbulent condition, positive IE was often larger than negative $H$, which produced negative EBR. This fact is the reason why EBR decreased at high $u^{*}$.
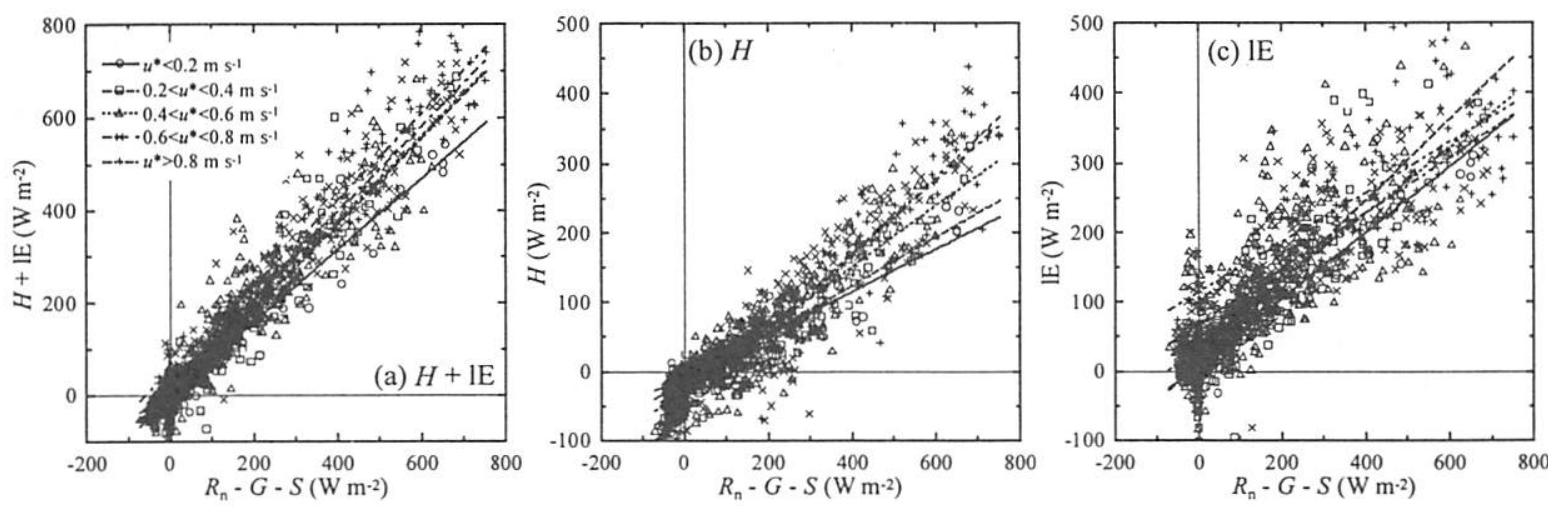

Fig. 4. Relationships between the half-hourly eddy energy flux and available energy during summer (July and August 2002). 

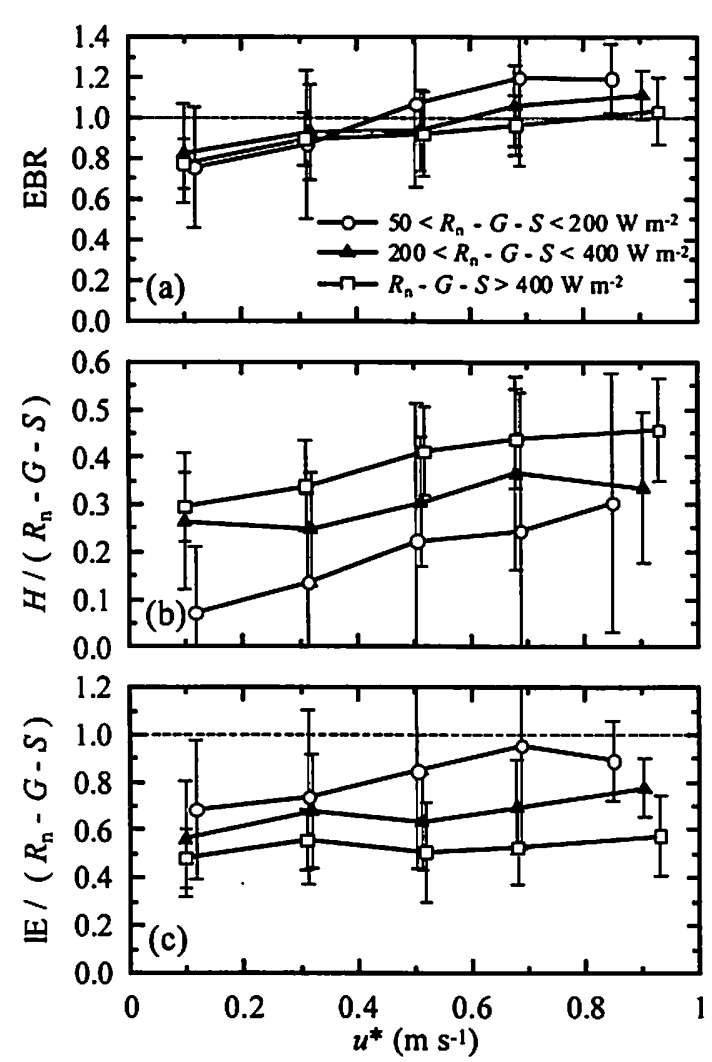

Fig. 5. Relationships between half-hourly (a) EBR, (b) $H /\left(R_{\mathrm{n}}-G-S\right)$ or (c) IE / $\left(R_{\mathrm{n}}-G-\right.$ $S$ ) and $u^{*}$ during summer (July and August 2002). Data were divided into three available energy classes and $u^{*}$ classes of $0.2 \mathrm{~m} \mathrm{~s}^{-1}$. Vertical bars denote standard variation.

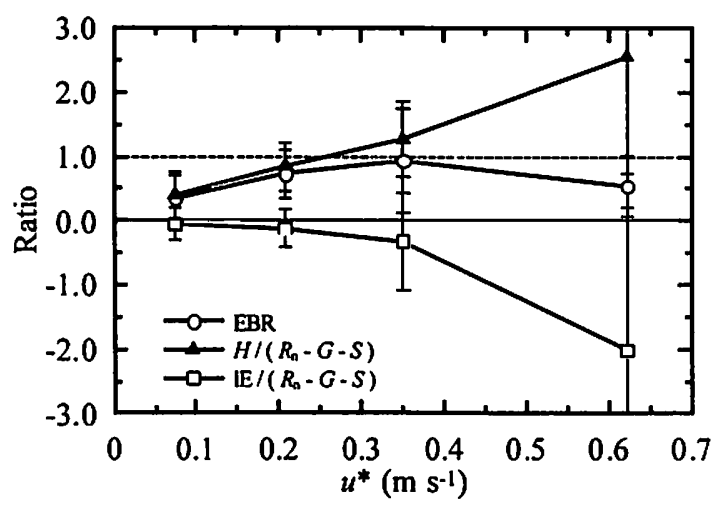

Fig. 6. Relationship between half-hourly EBR, $H /$ $\left(R_{\mathrm{n}}-G-S\right)$ or $\mathrm{IE} /\left(R_{\mathrm{n}}-G-S\right)$ and $u^{*}$ in the nighttime (available energy $\left(R_{\mathrm{n}}-G-S\right)<-20 \mathrm{~W}$ $\mathrm{m}^{-2}$ ) during summer (July to August 2002). Halfhourly mean data were divided into $u^{*}$ classes with the same number of data. Vertical bars denote standard variation.

\section{Acknowledgements}

This study was partly supported by a Grand-in-Aid for Scientific Research (No. 13480150) from the Ministry of Education, Culture, Sports, Science and Technology of Japan. We acknowledge the Hokkaido
Regional Office of the Forestry Agency for allowing the use of the larch forest, Yasuyuki Kitamori for maintenance of the instruments, Atsushi Toriyama for management of meteorological data.

\section{References}

Aubinet, M., Grelle, A., Ibrom, A., Rannik, Ü., Moncrieff, J., Foken, T., Kowalski, A. S., Martin. P. H., Berbigier, P., Bernhofer, Ch., Clement, R., Elbers, J., Granier, A., Grunwald, T., Morgenstern, K., Pielegaard, K., Rebmann, C., Snijders, W., Valentini, R., and Vesala, T. 2000: Estimates of the annual net carbon and water vapor exchange of forests: the EUROFLUX methodology. Adv. Ecol. Res., 30, 113-175.

Fujinuma, Y., Takada, M, Tashiro, K., and Inoue, G. 2001: GHGs flux monitoring at larch forest in Hokkaido, Japan. CGER-Report M-011 (Proc. International Workshop for Advanced Flux Network and Flux Evaluation), 161-164.

Hirano, T., Hirata, R., Fujinuma, Y., Saigusa, N., Yamamoto, S., Harazono, Y., Takada, M., Inukai, $\mathrm{K}$., and Inoue, G. 2003: $\mathrm{CO}_{2}$ and water vapor exchange of a larch forest in northern Japan. Tellus. 55B, 244-257.

Kaimal, J. C., and Finnigan, J. J., 1994: Atmospheric boundary layer flows. Oxford Univ. Press, New York, pp. 289.

Kormann, R., and Mexiner, F. X. 2001: An analytical footprint model for non-neutral stratification. Bound.-Layer Meteorol., 99, 207-224.

Miura, M., Hirano, T., Hirata, R., Mogami, J., Inukai, K., and Fujinuma, Y. 2003: Effect of heat storage flux on energy balance in a larch forest. J. Agri. Meteorol. 59, 245-250. (in Japanese with English summary)

Tanaka, H., Oguma, H., and Fujinuma, Y. 2003: A seasonal change of PRI and PPFD on the forest canopy. Proceedings of the 35th conference of the remote sensing society of Japan. 207-208.

Wilson, K., Goldstein, A., Falge, E., Aubinet, M., Baldocchi, D., Berbigier, P., Bernhofer, C., Ceulemans, R., Dolman, H, Field, C., Grelle, A., Ibrom, A., Law, B., Kowalski, A., Meyers, T., Moncrieff, J., Monson, R., Oechel, W., Tenhunen, J., Valentini, R., and Verma, S. 2002: Energy balance closure at FLUXNET sites. Agric. For. Meteorol. 113, 223-343. 